\title{
Assessment of the Essential Fatty Acids in Neonates at Risk for Atopy
}

\author{
Arnaldo Cantani* \\ Pediatric Clinic, University “La Sapienza” Roma, Italy
}

\begin{abstract}
Essential fatty acids (EFA) are the major components of cellular phospholipids (PLs), contributing to their stability and functions. They are also precursors of inflammation mediators such as prostaglandins and leukotrienes, and are involved in cellular immunoregulation.

Most recent studies have stressed that EFA levels are important in various diseases. Several Authors have stated that patients with atopic dermatitis (AD) have altered EFA levels in plasmatic PLs, and showed clinical improvement after oral EFA administration. The aim of our work was to study EFA composition of PLs of cord blood lymphocytes in 32 newborns at risk for atopy, in order to correlate EFA levels at birth with total $\lg E$ values and with the onset of atopic disease. Thirty not at risk newborns were studied as controls.

Our results demonstrate a significant decrease $(p<0.0001)$ of arachidonic acid $(A A)$ levels in lymphocytes of newborns at risk for atopy, compared to controls, whereas a not significant increase of linoleic acid (LA) was present. No reverse correlation between IgE values and AA levels was found, whereas the 6 month and 1 year follow-up have not shown any major alteration of total IgE values, on the contrary a normalization of AA levels in all but one child has been observed. Only this one child has developed AD. We stress that the preventive action on allergy development recognized to breast milk could be also due to its effect on the EFA composition of the PLs of cell membrane.
\end{abstract}

Keywords: Atopic dermatitis; Atopy; Essential fatty acids

\section{Introduction}

PUFA (polyunsaturated fatty acids) cannot be synthetized "de novo" by vertebrates from carbohydrates and aminoacids as all other lipids, and should be up taken through the diet. PUFA are the major components of PLs structured by cell membranes of which they share the physical state and functions [1]. Linoleic acid (LA) (C 18:2 n-6) is the main PL in mankind. By LA, by means of an enzyme system formed by elongate and desaturated, comes the arachidonic acid (C 20:4 n-6) (AA) and then, through the enzyme system formed by cyclo-oxygenase and lipoxygenase, a great number of biologically active molecules, the eicosanoids. This group includes Prostaglandins (PGs), Tromboxanes (Txs), Prostacyclins (PCs) and Leukotrienes (LTs).

The eicosanoid synthesis is induced in several cell types, including those of the immune systems through the activation of lypolytic enzymes (phospholipase), after adapt stimuli, coming from AA and dihomogammalinolenic acid (C 20:3 n-6) (ADGL) of structural membranous PL's. Hence, through the metabolic ways of 5- and 12-lipoxygenase and cyclo-oxygenase, and depending from the substratum availability, are formed some molecules whose biological activity is exercised upon a rich catalogue of physiological and pathological phenomena, also harmonising immune processes and cellular functions [2-6].

From the ADGL's arise the PGE-1's through the cyclo-oxygenase enzyme, which have an anti-inflammatory potential (or feebly inflammatory) and modulate with a mechanism of negative feed-back the AA release, in free form, from membranous deposits [7].

From the AAs the PGE-2s are drawn through the cyclo-oxygenase pathway and the group of LT-A4, B4, C4, and D4 through the lipoxygenase pathway.

In normal peoples the concentration of free AA is low [8]. moreover a part is ri-acylated by the acyltransferase enzyme pathway and re-incorporated in PLs in an esterified form $[9,10]$. As a result, whereas in spite of efficient homeostatic processes, the PL PUFA composition is regulated by the diet, the free AA levels available to be further metabolized reflect the enzymatic activity of phospholipase, acyltransferase, elongate, denaturise, cyclo- and lipoxygenase [10].

The first alterations described on the EFA metabolism in children affected by atopic dermatitis (AD), consist in the serum LA increase and in the contemporary decrease of its metabolites, such as ADGL and AA $[11,12]$. Several studies done in this field show, although with discordant results, positive therapeutic effects on the AD severity after dietetic supplementary LA and AGL [13-21].

A similar imbalance in the ratio between LA and AA was recently reported by Rocklin also in PLs of immunologically active cells such as the granulocytes and monocytes, in adult patients with respiratory allergy. Instead a contrary effect was found in the lymphocytes of the same patients [22]. Similar results were reported as changes in the AA metabolism in the platelets of adult patients suffering from respiratory allergy [10].

Several variables, especially those dietetic or referred to the intestinal fat absorption, may explain the contrasting results found by the authors. Notwithstanding the homeostasis, the making in fatty acids of platelet PLs is affected by the diet, by the ratio between fatty acids saturated or not present in PPs, by their absolute dose up taken daily, and type of EFA (n-6 or n-3) mainly represented [23,24].

A study [25] was done by dosing the EFAs in the cord serum (CS),

*Corresponding author: Arnaldo Cantani, Pediatric Clinic, University "La Sapienza" Roma, Italy, Tel: 0644230256; E-mail: acantani13@gmail.com

Received October 06, 2015; Accepted November 25, 2015; Published December 10,2015

Citation: Cantani A (2015) Assessment of the Essential Fatty Acids in Neonates at Risk for Atopy. J Biomol Res Ther 4: 133. doi:10.4172/2167-7956.1000133

Copyright: @ 2015 Cantani A. This is an open-access article distributed under the terms of the Creative Commons Attribution License, which permits unrestricted use, distribution, and reproduction in any medium, provided the original author and source are credited. 
to evaluate whether an inbalance exist already at birth and whether such an in balance is in the ratio with total IgE levels [25]. In this study, even if in a limited sample of babies not selection according to the atopy familiarity, the authors have shown that already at birth there were increased LA serum levels in the sample of new-borns with high levels of total IgE antibodies in the CS. These data suggests that the EFA imbalance could be a basal atopy characteristic and not only its consequence.

The object of this paper was to evaluate the EFA behaviour in the lymphocytes of neonates at risk for atopy and to prospectively evaluate the possible development of atopic diseases by correlating their appearance with the EFA levels at birth.

\section{Study Children}

We have selected for the present study 32 healthy term neonates at risk for atopy that is sons and/or brothers of atopic subjects (affected with asthma and/or rhinitis and/or AD) who were born in the Obstetric Clinic of the Roma University during the months of November-December 2004. At birth, $10 \mathrm{ml}$ of heparinized blood and $5 \mathrm{ml}$ of whole blood were collected by direct puncture of the umbilical cord, respectively, to dose the fat acids in the lymphocyte PLs and the blood dosing of total IgE antibodies. Thirty samples of heparinized blood coming from healthy new-borns, not at risk for atopy, were the controls. In each sample of heparinized blood there were immediately isolated both lymphocytes and monocytes on the Ficoll-Hipaque density gradient, thrice washed in PBS and counted. The cell pellet, after having added $100 \mu \mathrm{l}$ of an antioxidant such as Butylhydroxyanisole (BHA) to prevent and a specific oxidation of the fat acids have been stored a $-30^{\circ} \mathrm{C}$ until the performing of the specific analyses. In such a chance the pellet of lymphocytes and monocytes was beforehand lysed (re-suspended for 10 seconds in a hypo-osmotic buffer, $10 \mathrm{mM}$ TRIS pH 7.4) and centrifuged at 800 turnovers, then drawn with $3 \mathrm{ml}$ of chloroform-methanol-HCl $1 \mathrm{~N}$ (60:30:1) for 30 minutes. Then the solvent was then evaporated under a flow of hyper pure nitrogen at $60^{\circ} \mathrm{C}$.

The PLs were purified by thin-layer chromatography (TLC). The cellular lipid extract was then re-suspended in $100 \mu$ l of chloroformmethanol 2:1 (volume/volume), deposed on plates of silica gel (Merck), then migrated by a system of solvents constituted by hexane-ethyl etheracetic acid 70:30:1. The phospholipid fraction which by this system of solvent remained at the base of deposition was extracted thrice with $4 \mathrm{ml}$ of chloroform-methanol 1:1 and the solvent evaporated under nitrogen flow, $50 \mu \mathrm{g}$ of $\mathrm{C}$ 23:0 were added as an internal standard. The fatty acids of the phospholipid fractions were then trans-methylated by $\mathrm{B}$ fluorine in methanol (BF3/Met.10\%) to $80^{\circ} \mathrm{C}$ for 30 minutes and the fatty acid methyl esters so got were subsequently extracted with three volumes of hexane and the solvent evaporated. The fatty acid mixture was finally solubilized in $50 \mu \mathrm{l}$ of hexane and $2 \mu \mathrm{l}$ of this mixture were analysed in gas-chromatography. The following fatty acids were analyzed: Palmitic acid (C16), Stearic acid (C18), Oleic acid (C18:1), Linoleic acid (C18:2), AA (C20:4). The gamma and dihomo-gamma linoleic acids have been excluded by the statistical analysis because they are present, also in healthy people, but in very low levels because are rapidly transformed in their direct metabolite, the AA.

We have dosed the total IgE antibodies by the PRIST method using Phadebas PRIST (Pharmacia, Uppsala, Sweden).

The risk of neonates were subjected to dietetic and environmental protective measures for the prevention of atopic disease as reported in our previous paper [26] (Table 1), the study children were visited at the $3^{\text {rd }}-6^{\text {th }}$ month of life to ascertain the potential appearance of an atopic disease. The dietetic measures consisted in the exclusive breastfeeding for at least the first six months of life supplemented by a formula based on soy proteins, when the breast milk was not sufficient. In addition at the 6th month of life, in each child a sample was withdrawn to study the fatty acids in the lymphocyte PLs as well as the total IgE antibodies.

The $\mathrm{AD}$ diagnosis was done according to the criteria suggested by Hanifin [27].

\section{Results}

In the Table 2 we report the data regarding the 32 neonates at risk for atopy. The levels of the fatty acids palmitic, stearic, oleic, linoleic, AA. Regarding the statistical differences, our data show a highly significant decrease $(\mathrm{p}=0.0001)$ of the AA contrary to a statistically not significant increase of linoleic acid levels in the 32 at risk children, compared to 30 normal neonates of the control group.

Table 3 shows that the total IgE levels were higher than $0.8 \mathrm{UI} /$ $\mathrm{ml}$ only in $2 / 32$ at risk neonates and lower to $0.8 \mu \mathrm{l} / \mathrm{ml}$ in all the other babies.

In the Table 4 we report positive responses to $\mathrm{CM}$, egg and codfish. The mean AA concentration (expressed as per cent of the total fatty acids examined) in the UC (umbilical cord) lymphocytes compared to the geometric mean of total serum IgE levels. Evidently, no correlation was possible to demonstrate among total serum IgE levels and the corresponding AA values. In particular no inverse correlation was evident between the only two total IgE levels higher than $0.8 \mathrm{UI} / \mathrm{ml}$ and the AA decrease of the respective values (7.29\% and $12.79 \%)$.

We have carried out the two clinical follow-ups at six months and one year of life in 25 out 32 neonates enrolled at birth. In 11 of these babies we could make a blood sampling for their follow-up at the 6th month of life.

In $1 / 25$ babies appeared AD. Serum IgE values showed normal values for their age in all the engaged suckling. The study of the fatty

Prolonged and exclusive breastfeeding, extended, if possible, until the $6^{\text {th }}$ month of life,

Introduction of cow's milk and its derivatives beyond the $6^{\text {th }}$ month of life, of egg and fish beyond the first year,

When breast milk is insufficient, complete with a formula based on soy proteins until the $6^{\text {th }}$ month,

When breastfeeding is impossible, nourish the child with soy milk since birth by adding Ca (250 mg/day),

Selection weaning: since the $6^{\text {th }}$ month we suggest some fruit integration,

After the $6^{\text {th }}$ month we gradually introduce into the diet cow's milk and its derivatives, then gluten, while egg and fish are started beginning by the first year of age.

Settle a scrupulous environmental hygiene, especially in the child bedroom to limit the early exposition to potentially allergizing factors (house dust, wool, animal fur, must, etc.).

Abolition of full house cigarette smoke and of tobacco in general.

Delayed schooling: we suggest, when feasible, not to send the child to the kindergarten before the third year of age.

To the nursing mothers we suggest to restrict the cow's milk drinking, during the nursing, to a dose of 150-200 ml/day, and that of eggs (no more than two by week, preferably cooked).

We also prescribe an integration of both $\mathrm{Ca}$ and vitamins.

Ref. Cantani A, Arcese G. Prevention of atopic diseases: recent findings and personal data Eur Rev Med Pharmacol Sci 1992;14: 105-108.

Table 1: Environmental measures for the prevention of atopic diseases in high risk babies. 


\begin{tabular}{|c|c|c|}
\hline $\begin{array}{c}\text { At Risk New- } \\
\text { borns }\end{array}$ & Not At Risk & New-borns \\
\hline Palmitic (C16) & $37.2+/-9$ & $33.2+/-3.2$ \\
\hline Stearic (C18) & $37+/-16.5$ & $33.6+/-4.3$ \\
\hline Oleic (C18:1) & $11+/-4.8$ & $12.2+/-1.5$ \\
\hline Linoleic (C18:2) & $5.38+/-3.1$ & $5.06+/-0.7$ \\
\hline $\begin{array}{c}\text { Arachidonic } \\
\text { (C20/4) }\end{array}$ & $7.8+/-4.1$ & $13.5+/-4.3$ \\
\hline & p: 0 \\
\hline
\end{tabular}

Table 2: Fatty acids in \% values of total examined (M +/ 1SD) in the cord blood of 32 new-borns at risk of atopy and in 30 new-borns not at risk.

\begin{tabular}{|c|c|c|}
\hline Range & $0-388$ & $\mathrm{IU} / \mathrm{ml}$ \\
\hline Geometric mean & 49.8 & $\mathrm{IU} / \mathrm{ml}$ \\
\hline Median & 10.7 & $\mathrm{IU} / \mathrm{ml}$ \\
\hline
\end{tabular}

Table 3: Total IgE (PRIST)

\begin{tabular}{|c|c|}
\hline & Measured in 17/23 infants \\
\hline CM & $15 / 17$ at least \\
\hline Egg & one positive RAST \\
\hline & $15 / 17$ at least \\
\hline Wheat & one positive RAST \\
\hline Soy protein & $1 / 15$ more than \\
\hline & one positive RAST \\
\hline Codfish & $11 / 15$ more than \\
\hline & one positive RAST \\
\hline Dpt & $13 / 15$ more than \\
\hline & one positive RAST \\
\hline
\end{tabular}

Table 4: Antigen specific lgE (RAST).

acids of the lymphocyte membrane at the 6th month of life, has shown in 10 out of 11 babies the AA level normalization (AA: $15.3+/-3.73 \mathrm{M}$ $+/-1 \mathrm{SD}=$ values in $\%$ of the total of the examined fatty acids, whereas only in one baby out of 11 such value was significantly decreased in comparison with the controls (AA: $60.75=$ value in $\%$ of the total of the examined fatty acids). In such a child $\mathrm{AD}$ arose.

\section{Discussion}

This new study proves that in neonates at risk for atopy at birth is present in balance between LA and AA. We emphasize a significant AA decrease $(p=0.0001)$ in comparison with healthy controls.

Instead it was impossible to prove a correlation between total IgE levels and AA and LA values at birth. In particular, by considering that the only AA value that in our study is decreased in a highly significant way in comparison with the control babies, there is no inverse correlation among total IgE levels higher than $0.8 \mu \mathrm{I} / \mathrm{ml}$ and the respective AA values. We stress that only 2 babies out of 32 presented with IgE antibodies higher than $0.8 \mu \mathrm{I} / \mathrm{ml}$, therefore it is impossible to draw from these data any final conclusion. On the contrary it is true, as it is inferred from our former results, that also normal values of total IgE antibodies in the UC are consistent with a reduction also remarkable of AA levels in the lymphocyte membrane.

Instead the only study done on the UC underlined a correlation among increased LA plasma levels and high IgE levels $(>0.6 \mu \mathrm{l} / \mathrm{ml})$ [25]. However such a study, done on a slender number of cases, failed to specify whether the examined neonates had a positive familiarity for atopy.
The diminished AA values noted since birth in babies at risk for atopy, suggests that this anomaly could be primitive and then be regarded as a marker of the atopic status.

It appears to be interesting, although preliminary, the AA concentrations normalization in the lymphocytes seen at the control at the $6^{\text {th }}$ month of age. Really 9 of the 11 babies to whom we were able to withdraw a sample of blood at the $6^{\text {th }}$ month of age showed normal AA values. Two of them on the contrary still had significantly reduced values. Stimulating is our previous data that $\mathrm{AD}$ was manifested in one of these children.

We suggest that the dietetic and preventive measures which the babies followed during their first 6 months of life (Table 1) could have partly helped to correct the AA defect existing at birth. It is known that breast milk contains a proper PUFA amount and specifically from $g$ $0.27 \%$ to $g$ 0.40-0.48\% (w/v) of LA, and g $0.016 \%(w / v)$ of AA $[28,29]$.

If the present data were corroborated by a larger number of children, we could hypothesize that the breast milk preventive action on the atopic disease development could be also due to its effect on EFA composition in PL's of cell membrane.

We have demonstrated, by partly confirming the previous results, an AA primitive decrease in membrane PL's, that may take a pathogenetic weight for at least two motives.

A first motive of interest attests that our results give credit to the hypothesis already drawn out by additional studies, of an enzyme deficit regarding the delta-6-desaturase, the first enzyme of the sequence forming AGL by adding a double link to LA [30]. We could also hypothesize a reduced ADGL production and then of PGE-1. Their relative deficit (as previously mentioned), might lose the negative feedback mechanism performed on AA, leading to its continuing release from deposits, and making its available to form preferably eicosanoids with high pro-inflammatory activity such as PGE-2 and LTB-4.

LTB-4 is a mighty pro-inflammatory agent with a chemotactic power towards polymorphonuclears, eosinophils and monocytes and it was found significantly increased in the skin areas with the $\mathrm{AD}$ eczematous lesions [31]. Such a finding could be of pathogenetic relief since monocytes and macrophages are high LTB- 4 producers and accordingly favour the establishment of an amplifying, auto-lasting mechanism in the seats of skin inflammation.

However PGE-1s are mighty drivers of the cAMP formation and modulate the intracellular Ca release (7), thus inciting an abated $\mathrm{Ca}$ discharge. Thus the PGE-1 lack could confirm and enlarge the Hanifin hypothesis, which in a recent paper shows that in $\mathrm{AD}$ patients exist low levels of phosphorylation of proteinchinase-C, which is a Ca- and PLdependent enzyme [32].

Previous studies to that by Hanifin report in AD a cAMP lower intracellular levels, which act by inhibiting the cellular functions, also demonstrating low cAMP levels in leukocytes of $\mathrm{AD}$ patients after exposure to agents activating the adenylate-cyclase enzymes including the beta-2-stimulants, PGE-1s and histamine [33-35]. The same Hanifin group has in addition shown in leukocytes of AD patients a heightened phosphodiesterase activity, the enzyme catalysing cAMP, and suggested that the decreased proteinchinase- $\mathrm{C}$ activity may be taken as responsible of an altered phosphorylation of the phosphodiesterase itself, making it hyperactive. That could lead, through a reduction of cAMP levels, and consequently, to the state of pharmacologic and immunologic hyper reactivity existing in $\mathrm{AD}[32,36]$. 
Another interesting PGE-1s aspect involve their value in the mechanisms of cellular immunoregulation: they appear to be vital for a normal $\mathrm{T}$ lymphocyte function. PGE-1s are in fact present in a good deal in the thymus, where they likely exert functions joined to the $\mathrm{T}$ lymphocyte system maturation and evolution, in the presence of proper Zn levels, that appear to be necessary for PGE-1 biosynthesis [37]. In $\mathrm{AD}$ were delineated either changes of $\mathrm{Zn}$ levels, or disorders of T lymphocytes [38].

A second motif of interest is due to the defective EFA levels, which can explain some basal characteristics of $\mathrm{AD}$ patients: the extreme dryness, the scariness, the lichenification, the utmost sensibility to pruritus to which the skin is predisposed and that appears to be preferable to the cholinergic stimulation and to the cAMP decreased levels $[39,40]$.

In the lower part of the horny layer, just under the granular layer, there is a lipid "barrier", rich of LA, necessary for a good state of hydration and waterproofing. These lipids are secreted by particular granular formations called Odland bodies, which were found to be abnormal in the dry not eczematous skin of atopic patients [41].

Nevertheless the healthy skin cannot metabolize either AGL from LA or AA from ADGL because it lacks the denaturises enzymes and therefore wholly depends for their contributions from the metabolism of others organs, above all by the liver [42].

In conclusion, just the child who had at the 6th month of life a permanency of the low $A A$ values present at birth fell sick of $A D$, strengthens the datum that the metabolic EFA alterations play a role in the skin features of such disorder.

\section{References}

1. Brenner RR (1984) Effect of unsaturated acids on membrane structure and enzyme kinetics. Prog Lipid Res 23: 69-96.

2. Staite ND, Panavy GS (1984) Prostaglandin regulation of B-lymphocyte function. Immunol Today 5: 175-178.

3. Henderson WR Jr (1987) Eicosanoids and Lung Inflammation. Am Rev Respir Dis 135: 1176-1185.

4. Rola-Pleszcynski M (1985) Immunoregulation by leukotrien- es and other lipoxygenase metabolites. Immunol Today 6: 302-306.

5. Assel C, Mary C, Fehlman M (1987) Prostaglandin synthesis in human T cells: its partial inhibition by lectin and anti-CD3 antibody as a possible step in T cell activation. J Immunol 138: 3094-3099.

6. Goodman MG, Brunton LL, Weigle WO (1981) Modulation of Iymphocyte activation II: alteration of intracellular cyclic nucleotide concentration by an oxidation product of arachidonic acid. Cell Immunol 5: 85-96.

7. Horrobin DF (1980) The regulation of prostaglandin biosyntesis: negative feed-back mechanisms and the selective control of formation of 1 and 2 series prostaglandins: relevance to inflammation and immunity. Medical Hypotheses 6: 687-709.

8. Borgeat P, Nadeau M, Salari H, Poubelle P, Freteau de Laclos B (1985) Leukotrienes: biosyntesis, metabolism, and analysis. Adv Lipid Res 21: 47-77.

9. Lans DM, Rocklin RE (1989) Dysregulation of arachidonic acid release and metabolism by atopic mononuclear cells. Clin Exp Allergy 19: 37-48.

10. Audera C, Rocklin R, Vaillancourt R, Jakuboswski JA, Deykin D (1988) Altered arachidonic acid metabolism and platelet size in atopic subjects. Clin Immunol Immunop athol 46: 352-359.

11. Hansen AE (1933) Serum lipid changes and therapeutic effect of various oils in infantile eczema. Proc Soc Exp Biol Med 31: 160.

12. Hansen AE (1937) Serum lipids in eczema and other pathological conditions Am J Dis Child 53: 933-946.

13. Cornbleet $T$ (1935) Use of maize oil (unsaturated fatty acids) in the treatment of eczema. Arch Dermatol Syph 31: 224-234.

14. Ginsberg JE, Bernstein C (1937) Effect of oils containing unsaturated fatty acids on patients with dermatitis. Arch Dermatol Syph 36: 1033-1035.
15. Finnerud CW, Kesler RL, Wiese HF (1941) Ingestion of lard in the treatment of eczema and allied dermatoses. Arch Dermatol Syphil 44: 849-853.

16. Hansen AE, Knott EM, Wiese HF, Shaperman E, Mc Quarie I (1947) Eczema and essential fatty acids. Am J Dis Child 73: 1-18.

17. Taub SJ, Zakon SJ (1935) Use of unsaturated fatty acids in the treatment of eczema. JAMA 105: 1675

18. Pettit JHS (1954) Use of unsaturated fatty acids in the eczemas of childhood BMJ 1: 79-81.

19. Lovell CL, Burton JL, Horrobin DF (1981) Treatment of atopic eczema with evening primerose oil. Lancet 1: 278-281.

20. Weight S, Burton JL (1982) Oral evening-primrose-seed oil improves atopic eczema. Lancet 2: 1120-1122.

21. Skogh M (1986) Atopic eczema unresponsive to enening-primerose oil linoleic and gamma-linolenic acids. J Am Acad Dermatol 15: 114-115.

22. Rocklin RE, Thistle L, Gallant L, Manku MS, Horrobin D (1986) Altered Arachidonic acids content in polymorphonuc lear and mononuclear cells from patients with allergic rhinitis and/or asthma. Lipids 21: 17-20.

23. Ferretti A, Judd JT, Taylor PR, Schatzkin A, Brown C (1989) Modulating influences of dietary lipid intake on the prostaglandin system in adult men. Lipids 24: 419-422.

24. Lokesh BR, Black JM, Kinsella JE (1989) The suppression of eicosanoid synthesis by peritoneal macrophages is influenced by the ratio of dietary docosahexaenoic acid to linoleic acid. Lipids 24: 589-593.

25. Strannegard IL, Svennerholm L, Strannegard O (1987) Essential fatty acids in serum lecithin of children with atopic dermatitis and umbelical cord serum of infants with high or low IgE levels. Int Arch Allegy appl Immunol 82: 422-423.

26. Businco L, Cantani A, Meglio P, Bruno G (1987) Prevention of atopy: results of long-term (7 month to $8 \mathrm{yr}$ ) follow-up. Ann Allergy 59: 183-186.

27. Hanifin JM, Rajk G (1980) Diagnostic features of atopic dermatitis. Acta Dermatol Veneorol 92: 44-47.

28. Clinical Nutrition: Essential fatty acids deficiency in premature infants (1989) In: "Nutrition Reviews" 47: 39-41.

29. Gibson RA, Kneebone GM (1981) Fatty acid composition of human colostrum and mature breast milk. Am J Clin Nutr 34: 252-257.

30. Manku MS, Horrobin DF, Morse NL, Wright S, Burton IJ (1984) Essential fatty acids in patients with atopic eczema. Br J Dermatol 110: 643-648.

31. Ruzicka T, Simmet T, Peskar BA, Ring J (1986) Skin levels of Arachidonic acid-derived inflammatory mediators and histamine in atopic dermatitis and psoriasis. J Invest Dermatol 86: 105-108.

32. Trask DM, Chan SC, Sherman SE and Hanifin JM (1988) Altered leukocyte protein kinase activity in atopic dermatitis. J Invest Dermatol 90: 526-531.

33. Safko MJ, Chan S, Cooper KD, Hanifin JM (1981) Heterolougus desensitization of leukocytes: a possible mechanism of beta-adrenergic blockade in atopic dermatitis. J All Clin Immunol 68: 218-225.

34. Parker CW, Kennedy S, Eisen AZ (1977) Leukocyte and lymphocyte cyclic AMP reaction in atopic eczema. J Invest Dermatol 68: 302-306.

35. Busse WW, Lantis SDH (1979) Impaired H2 histamine granulocyte response in active atopic eczema. J Invest Dermatol 73: 184-187.

36. Grewe SR, Chan S, Hanifin JM (1982) Elevated leukocytes cAMPphosphodiesterase in atopic disease. A possible mechanism for CAMP-agonist hyporesponsiveness. J All Clin Immunol 70: 452-457.

37. Horrobin DF, Hanku MS, Oka M, et al. (1979) The nutritional regulation of T lymphocyte function. Med Hypoth 5: 969-985.

38. Rachelefsky GS, Opels G, Michey MR, Kiuchi M, Terasaki PI, et al. (1976 Defective T-cell function in atopic dermatitis. J All Clin Immunol 57: 569-576.

39. Moa Schalin K, Leena Mattila CT, Jansen T, Pekka U (1987) Evening primrose oil in the treatment of atopic eczema: effect on clinical status, plasma phospholipid fatty acids and circulating blood prostaglandin. Br Med J Dermatol 117: 11-19.

40. Burton JL (1989) Dietary fatty acids and inflammatory skin disease. Lancet 1: 27-30.

41. Werner $Y$, Lindberg $M$, Forslind $B$ (1987) Membrane-coating granules in 'dry' non eczematous skin of patients with atopic dermatitis. Acta Dermatol Venereol 67 385-390.

42. Horrobin DF (1989) Essential fatty acids in clinical dermatology. J Am Acad Dermatol 20: 1045-1053. 